\title{
Fabrication and Assessment of a Thin Flexible Surface Coating Made of Pristine Graphene for Lightning Strike Protection
}

\author{
B. Zhang ${ }^{1}$, S. A. Soltani ${ }^{2}$, L. N. Le ${ }^{1}$, R. Asmatulu ${ }^{1} *$ \\ ${ }^{1}$ Department of Mechanical Engineering, ${ }^{2}$ Department of Aerospace Engineering \\ Wichita State University, 1845 Fairmount st., Wichita, KS 67260-0133 \\ *Corresponding author: ramazan.asmatulu@wichita.edu
}

\begin{abstract}
A thin flexible coating made of pristine graphene was fabricated and applied on the surface of a commercial carbon fiber epoxy prepreg laminate to protect it against the lightning strike. To assess the coating's effectiveness, the coated laminate was subjected to the simulated lightning strike as well as the electromagnetic interference shielding effectiveness (EMI SE) testing. It was observed that the damaged area and volume in the coated laminate were reduced by $94 \%$ and $96 \%$, respectively, as compared to the laminate without the coating. Moreover, the coated laminate had an average EMI SE of $51 \mathrm{~dB}$ over 100-2000 MHz range, $55 \mathrm{~dB}$ over 8-12 $\mathrm{GHz}$ range, and $60 \mathrm{~dB}$ over $12-18 \mathrm{GHz}$ range marking $22 \%, 44 \%$, and $49 \%$ improvement in EMI SE for each frequency range, respectively. The results indicate a great potential for the developed coating to protect the commercially available prepreg composites against the lightning strike.
\end{abstract}

Keywords: Polymer-matrix composites; Graphene Coating; Lightning Strike Protection. 


\section{Introduction}

It is estimated that every commercial aircraft experiences a direct lightning strike once every year. However, since the aircraft skin is conventionally made of aluminum which is an electrically conductive material, the physical damage of lightning strike has often been limited to the burn marks on the skin and the trailing edges. Also, the aircraft metallic skin acts as a Faraday cage during lightning strike, protecting the avionics from electromagnetic interference (EMI) [1].

With the advent of composite materials in aerospace structures, protecting aircraft against lightning strike has become an important task since the fiber reinforced polymer composites (FRPCs) are considerably less conductive as compared to their metallic counterparts [2, 3]. Several methods have been employed in aerospace industry for lightning strike protection (LSP) of composite structures. The main functionality of LSP is to provide a continuous conductive path throughout the aircraft exterior especially in the zones more susceptible to lightning strike such as nose, wingtips, nacelles, radomes and extremities of the empennage. Commonly, LSP consists of a lightweight metallic mesh or foil made mainly of aluminum or copper and to a lesser extent phosphor bronze, titanium embedded in the outmost laminate ply which connects the outer surface to a metallic ground plane such as an engine [4-6]. Nevertheless, the metallic meshes embedded in carbon fiber structures increase the weight of the structure. Moreover, they are susceptible to pitting, oxidation and galvanic corrosion, and hence lose their electrical conductivity over the time [7]. To embed the mesh more effectively in the composite structure, many aerospace material suppliers impregnate the metallic mesh with adhesive films, surfacing films, or prepregs. More recently, highly conductive nonwoven veils fabricated with randomly oriented nickel or copper coated carbon fibers and prepregs made with continuous fibers coated 
using nickel vapor deposition have been developed and tested for LSP applications. Sprayable conductive paints or surfacing films made with nickel nanostrand enhanced polymeric materials is another LSP method currently being considered for aerospace applications [5].

As an alternative solution to the current state-of-the-art in the aerospace industry, nanomaterials such as carbon nanofibers, nickel nanostrands, graphene, and carbon black have been shown to enhance electrical and mechanical properties of FRPCs [8-14]. Gou et al. [8] developed a special paper made of carbon nanofibers and nickel nanostrands and used it as a coating for carbon fiber reinforced polyester composites fabricated with resin transfer molding. Zhang et al. [9] reported that inclusion of $3 \mathrm{wt} . \%$ of carbon black and copper chloride in the resin, effectively improved electrical conductivity hence lightning strike protection of carbon fiber reinforced epoxy composites. Yamamoto et al. [12] observed that electrical conductivity of alumina fiber reinforced laminates exceeded $100 \mathrm{~S} / \mathrm{m}$, marking a 6-8 orders of magnitude improvement as compared to the baseline after $1.5 \mathrm{wt} . \%$ aligned carbon nanotubes were directly grown onto the fiber mat. Morales et al. [11] reduced electrical resistivity of polyester glass fiber composites from the fully insulator down to $10^{3}-10^{5} \Omega$ by adding 0.5 wt. $\%$ to 1 wt. $\%$ carbon nanofibers to the resin. The panels in their study were fabricated by hand lay-up and vacuum bagging. Domingues et al. [13] improved the through-the-thickness conductivity of glass finer epoxy composites fabricated using resin infusion by an order of magnitude to $1.4 \times 10^{-3} \mathrm{~S} / \mathrm{m}$ by inclusion of $0.1 \mathrm{wt} . \%$ nanotubes into the resin.

Besides physical damage, the lightning strike results in electromagnetic interference (EMI) which could cause severe safety concerns for the advanced avionics equipment in an aircraft [15-17]. The magnetic fields can be calculated by: 
where $H$ is the field strength $(\mathrm{A} / \mathrm{m}), I$ is the lightning current (A), and $r$ is the distance between the fuselage and the lightning channel, and $\pi$ is a constant (equal to 3.14) [18]. Finding an efficient way to eliminate or shield the electromagnetic interference is a critical factor in designing aircraft. As shown in Figure 1, EMI shielding mechanisms include reflection, absorption, and multiple reflections of electromagnetic radiation to prevent it from penetrating through the material. The shielding material needs to have electrons and holes present, in order to act as mobile carriers to interact with the electromagnetic field. Consequently, shielding materials become electrically conductive. Furthermore, electric and magnetic dipoles are the essential absorption properties of shielding materials because they can interact with the electromagnetic fields when EMI occurs. Shielding materials have high values for the dielectric constant and provide more electric and magnetic dipoles [19-25]. The shielding effectiveness (SE) of a material can be estimated using the following equation:

$$
S E_{\text {Total }}=S E_{A}+S E_{R}+S E_{M R}
$$

where $S E_{\text {Total }}$ is the total shielding effectiveness, $S E_{A}$ is the shielding effectiveness due to absorption, $S E_{R}$ is the shielding effectiveness due to reflection, and $S E_{M R}$ is the shielding effectiveness due to multiple reflections [26]. The shielding effectiveness depends on the material characteristics as well as the frequency of the electromagnetic field. On one hand, $S E_{R}$ increases with increasing electrical conductivity and $S E_{A}$ increases with increasing magnetic permeability. On the other hand, $S E_{R}$ mainly decreases, and $S E_{A}$ increases with increasing the frequency of the electromagnetic field. Combined reflection and absorption, or multiple reflections, is another mechanism of EMI shielding. This requires both a large surface area and shielding interface area. Fiber-reinforced polymeric nanocomposites are a typical example of 
shielding with a large interface area, and they form porous materials having a shielding property with a large surface area [27]. Therefore, EMI shielding effectiveness includes the total loss, in decibels $(\mathrm{dB})$, from absorption, reflection, and multiple reflections. The SE is affected by the thickness of the shielding skin. EMI only interacts with the upper-surface region, if it is of a high frequency; therefore, the skin depth $(\delta)$ where the electric field drops to 1/e of the incident value is given as

$$
\delta=\frac{1}{\sqrt{\pi f \mu \sigma}}
$$

where $f$ is the frequency, $\mu$ is the magnetic permeability, and $\sigma$ is the electrical conductivity ( $\mathrm{S} / \mathrm{m})$.

FRPCs, unlike metals, are vulnerable to EMI due to the inherent electrical insulating properties of polymers. The EMI shielding effectiveness of FRPCs can be improved by enhancing their electrical properties using nanomaterials [12, 28-32]. Table 1 shows the EMI shielding effectiveness of different nanocomposite materials. It has been shown that at low frequencies, absorption is the primary EMI shielding mechanism in polymer Nanocomposites enhanced by carbon nanofillers $[33,34]$. Moreover, several studies have concluded that conductive fillers with a higher aspect ratio, $L / D$ (where $L$ is the length and $D$ is the diameter or thickness of the nanofiller particles) offer better EMI shielding effectiveness than conductive fillers with a lower aspect ratio $[35,36]$. Amongst all carbon based nanomaterials, graphene sheets provide the best protection against EMI [37]. This was attributed to the high aspect ratio of graphene sheets as well as formation of a 3D network which helps establish a close contact between the particles dispersed in the polymer. More recently, Song et al. reported shielding effectiveness of up to $27 \mathrm{~dB}$ for paraffin-based sandwich structures enhanced with multilayer graphene/polymer composite films [38]. 
Since many composite structures are currently made of prepreg composites cured in an oven or autoclave, it is important to investigate novel methods to protect prepreg laminates against lightning strikes. In this study, the effectiveness of a novel coating made of pristine graphene to protect carbon fiber epoxy prepreg laminates against lightning strike is investigated. For the panels protected with the coatings, the reduction in physical damage as well as the effectiveness of EMI shielding are reported and compared with the base panel fabricated with no coating.

\section{Experimental}

\subsection{Materials}

The composite laminates were made using MTM® 45-1 epoxy prepreg reinforced by Toray T-800S 24k unidirectional carbon fiber with 196 gsm fiber areal weight and 32\% resin content supplied by Advanced Composites Group (Tulsa, Oklahoma). The pristine graphene powder (product number: N006-010-P) was purchased from Angstron Materials, Inc. (Dayton, Ohio). The physical dimensions of this fine grayish-black carbon in powder form are less than $5.00 \mu \mathrm{m}$ in the $\mathrm{x}$ and $\mathrm{y}$, and $50-100 \mathrm{~nm}$ in the $\mathrm{z}$ dimension. Pristine graphene contains $0.6 \%$ hydrogen, $0.5 \%$ nitrogen, and $0.8 \%$ oxygen.

\subsection{Methods}

\subsubsection{Fabrication of Graphene Thin Film}

To fabricate the graphene thin film, 4 grams of pristine graphene was mixed and stirred with $500 \mathrm{~mL}$ deionized water in a flask for one day. The solution was then lab-scale sonicated at $20 \mathrm{kHz}$ using an FS60D sonicator (Fischer Scientific, Pittsburg, PA) for two hours before it was dried on a pre-wetted glass fiber filter paper to obtain the graphene film. The filter paper was 
placed on top of a funnel connected to the vacuum pump. Subsequently, the flask solution was poured into the funnel. To peel off the graphene film from the filter paper, another filter was placed on top of it to sandwich the graphene film. The filter was then compressed using an aluminum cylinder roller and removed by hand using a pair of tweezers. The fabrication process of the graphene film is illustrated in Figure 2. As explained later, several thin films with a variety of thicknesses and electrical conductivities were fabricated using this process. The electrical conductivity measurement method is explained by Kumar [39]. The density of fabricated thin films measured per ASTM D 792 was $\sim 2 \mathrm{~g} / \mathrm{cm}^{3}$.

\subsubsection{Fabrication of Panels}

First, the aluminum tool plate was prepared by applying the sealer agent and mold release. Then, a single layer of pristine graphene thin film measured $406 \mathrm{~mm}$ by $406 \mathrm{~mm}$ by $0.1 \mathrm{~mm}$ was placed on the surface of the aluminum panel before laying up the prepreg layers. The prepreg was cut into $508 \mathrm{~mm}$ by $508 \mathrm{~mm}$ plies, eight prepreg plies in [0/90] $]_{4 \mathrm{~T}}$ order were placed atop the pristine graphene layer, and then the panels were cured in an oven using manufacturer's recommended cure cycle that is cure at $88^{\circ} \mathrm{C}$ for 3 hours followed by post cure at $121^{\circ} \mathrm{C}$ for 3 hours. The cured panel thickness was about $1.1 \mathrm{~mm}$. The prepreg control panel was fabricated similarly without applying the graphene thin film.

\subsubsection{Lightning Strike Simulation Test}

Figure 3 (a) illustrates the schematic of lightning strike test setup. Figure 3 (b) shows the current components A though D used for the simulated lightning strike test. These current components represent the lightning flash current waveforms recommended by MIL-STD-464C for evaluating the direct effect of lightning strike [40]. Component A simulates the initial strike, whereas components $\mathrm{B}$ and $\mathrm{C}$ simulate the lightning environment possibly caused by the 
intermediate and long duration currents after the initial strike or restrikes, and component D simulates a subsequent strike [41]. The peak current in components B and $\mathrm{C}$ is much lower than that in components A and D. Since the charge transfer in components B and C is very high, these components can be assumed as the bridge between the initial strike $\mathrm{A}$ and the subsequent strike D. Note that components A through D represent an idealized environment not intended to replicate any specific lightning event. The peak current, time duration and action integral are the primary parameters that influence the response of the structure. Note that the action integral represents the intensity of the strike. As such, to make sure that the simulated test accurately represents a real lightning, it is important to keep the action integral as high as specified by the requirements [41].

The recorded experimental current data used in the lightning strike test setup for components A to D were as follows: no current at component A, $3.9 \mathrm{kA}$ at component $\mathrm{B}, 0.424$ $\mathrm{kA}$ at component $\mathrm{C}$, and $100 \mathrm{kA}$ at component $\mathrm{D}$. The coated side of the composite panels was facing the current probe in the test setup. One graphene coated panel and one control panel were tested subsequently.

The performance of LSP against the direct effect of lightning strike could be assessed by measuring the damage volume and area through ultrasonic testing and also measuring the residual mechanical strength of the damaged panels by performing mechanical testing such as compression and tension $[8,41-43]$.

\subsubsection{EMI Shielding Effectiveness Test}

The EMI shielding effectiveness was tested using a reverberation chamber over the frequencies ranges of $100-2000 \mathrm{MHz}$ and 8-18 GHz. As illustrated in Figure 4, the chamber consisted of two separate metal compartments (Tx side and Rx side) attached only by a $610 \mathrm{~mm}$ 
by $610 \mathrm{~mm}$ access panel to allow for complete isolation between the compartments. The reverberation chamber is capable of creating isotropic, uniform, and randomly polarized fields. The panels under testing were exposed to this randomly polarized field, which led to a more robust test than a single plane-wave measurement on each panel.

The test setup was designed to maximize the field exposure of the test panels. The transmission reverberation chamber used was $5.2 \mathrm{~mm}$ by $7.6 \mathrm{~m}$ by $3.7 \mathrm{~m}$ and utilized a large 3.4 m-tall paddle wheel, both of which helped create a uniformly distributed field at frequencies as low as $100 \mathrm{MHz}$. The reception compartment was $4.6 \mathrm{~m}$ by $2.4 \mathrm{~m}$ by $3.7 \mathrm{~m}$, which had previously been used as an amplifier room. Without a reception-side paddle wheel, there was no certainty that the reception-side antenna had been exposed to the peak field passing through the test panels. Therefore, for more accurate measurements of the peak field strength in the reception chamber, a paddle wheel was also installed. This paddle wheel stirred any energy that passed through the test panels around the room until that energy was picked up at the Rx antenna. The transmission and reception compartments were completely separate from each other, except for a $610 \mathrm{~mm}$ by $610 \mathrm{~mm}$ access panel between them. This room separation minimized the field leakage between compartments that would limit the dynamic range.

An input power of $50 \mathrm{~W}$ was used throughout testing. Measurements were first taken without a panel installed in the test fixture. This led to an open-hole measurement of all energy that was transferred from the transmission room to the reception room. A test panel was then installed in the fixture. The same input power of $50 \mathrm{~W}$ was applied to the transmission compartment. The energy measured on the reception side with a test panel installed was compared to the open-hole measurement. The difference between the open-hole reference measurement and the test-panel measurement was considered to be the shielding effectiveness of 
the material. The open-hole reference and test-panel measurements both contained all chamber insertion losses, so when the difference between the measurements was calculated, the insertion loss was essentially cancelled out of the final SE value.

\section{Results and Discussion}

Table 2 contains the thickness and electrical conductivity of 8 different graphene thin films fabricated for this study. As it can be seen, the thinner the film the higher the electrical conductivity. This was expected since the graphene layers are bonded by weak pz interactions in through-the-thickness direction [44] which means thicker samples will have more weak pz interactions hence lower electrical conductivity in through-the-thickness direction. Two factors affected the choice of graphene film thickness for application on the prepreg surface: 1) electrical conductivity and 2) handleability. While it was desired to apply the most conductive graphene layer on the prepreg surface, the experimental trials proved that graphene layers thinner than 0.1 $\mathrm{mm}$ were more difficult to handle. As such, the $0.1 \mathrm{~mm}$ thick graphene film was selected for further study. Figure 5 shows the noticeable flexibility of the $0.1 \mathrm{~mm}$ thick film. The observed flexibility suggests that the thin film could be easily applied on the surface of the parts with contoured shapes and complicated geometries especially for the aerospace, wind turbine and many other applications.

\subsection{Lightning Strike Simulation}

The 2-D and 3-D images of the panels after simulated lightning strike test obtained by ultrasonic testing are shown in Figures 6-a and 6-b. The top two images illustrate 3-D view of the damaged volume observed from two different angles. The color scale on the right hand side of 


\subsection{EMI Shielding Effectiveness}

Figure 7 depicts the measured EMI SE over the microwave (100-2000 MHz) and the X- 
band $(8-12 \mathrm{GHz})$, and the $\mathrm{Ku}$ band $(12-18 \mathrm{GHz})$ for the panel coated with graphene thin film as well as the control panel. As is seen in Figure 7, the coated laminate exhibited better EMI SE over the entire frequency range. More specifically, the coated laminate had an average EMI SE of $51 \mathrm{~dB}$ over the microwave range, $55 \mathrm{~dB}$ over the X-band, and $60 \mathrm{~dB}$ over the Ku-band marking 22\%, $44 \%$, and 49\% improvement in EMI SE for each band, respectively. These results are particularly important since they indicate that by placing a thin graphene film on the surface of a commercial carbon fiber prepreg laminate, the laminate's shielding effectiveness can match that of nanocomposites shown in Table 1.

Note that the EMI SE below $200 \mathrm{MHz}$ seems to drop. This drop was likely due to the less energy being transferred during the open-hole measurement because the test frequency wavelength was too large to efficiently pass through the $279 \mathrm{~mm}$ by $279 \mathrm{~mm}$ test-fixture opening. This drop in energy caused the dynamic range of the test setup to be reduced. The noise floor of the spectrum analyzer was $110 \mathrm{dBm}$ for the frequencies below $1 \mathrm{GHz}$. For frequencies above 1 $\mathrm{GHz}$, the noise floor was extended down to $-130 \mathrm{dBm}$ with the use of a pre-amplifier. All frequencies used during testing showed an acceptable stir ratio (maximum point measured over minimum point measured) of $20 \mathrm{~dB}$, which indicates a uniform field distribution throughout the testing.

To further investigate EMI SE of the graphene coated panel, the theoretical $S E_{\text {Total }}$ was calculated using the available literature [38, 47-49] under far field electromagnetic source condition, that is the existence of a uniform plane wave incident normal to the surface of the shield. Since the graphene film was significantly more conductive than the composite laminate, the shielding effectiveness was calculated for the graphene thin film only. To obtain the components of $S E_{\text {Total }}$ as defined by Eq. 2, first the skin depth was estimated using Eq. 3 
knowing that $\sigma$ for the graphene thin film is $2.14 \times 10^{4} \mathrm{~S} / \mathrm{m}$ and $\mu$ is $4 \pi \times 10^{-7} \mathrm{H} / \mathrm{m}$ [47]. Figure 8 illustrates the skin depth $(\delta)$ as a function of frequency. It is notable that for frequencies above 1 $\mathrm{GHz}$, the skin depth was smaller than the thickness of the graphene thin film which means the effect of multiple reflections on the total shielding effectiveness was negligible. The shielding effectiveness due to the reflection $\left(S E_{R}\right)$ was calculated using the following equation [47]:

$$
S E_{R}=20 \log \left(\frac{1}{4} \sqrt{\frac{\sigma}{2 \pi f \mu_{r} \varepsilon_{0}}}\right)
$$

where $S E_{R}$ is the reflection shielding effectiveness $(\mathrm{dB}), f$ is the frequency $(\mathrm{Hz}), \sigma$ is the graphene thin film electrical conductivity equal to $2.14 \times 10^{4} \mathrm{~S} / \mathrm{m}, \mu_{r}$ is the relative magnetic permeability of graphene equal to 1 [47], and $\varepsilon_{0}$ is the vacuum permittivity equal to $8.85 \times 10^{-12} \mathrm{~F} / \mathrm{m}$. The shielding effectiveness due to absorption $\left(S E_{A}\right)$ was calculated using the following equation [47]:

$$
S E_{A}=8.6859 \frac{t}{\delta}
$$

where $S E_{A}$ is the absorption shielding effectiveness (dB), $t$ is the thickness of the graphene thin film (m), and $\delta$ is the skin depth (m). The shielding effectiveness due to multiple reflections $\left(S E_{M R}\right)$ was calculated using the following equation [38]:

$$
S E_{M R}=20 \log \left|1-e^{\frac{-2 t}{\delta}}\right|
$$

where $S E_{M R}$ is the multiple reflections shielding effectiveness $(\mathrm{dB}), t$ is the thickness of the graphene thin film (m), and $\delta$ is the skin depth (m). Figure 8 depicts the calculated $S E_{\text {Total }}, S E_{R}$, $S E_{A}$, and $S E_{M R}$ values as a function of frequency for the graphene film. Note that as frequency increased, $S E_{\text {Total }}$ and $S E_{A}$ increased and $S E_{R}$ decreased. This was expected since per Eq. 4, reflection loss is more dominant at lower frequencies and drops at a rate of $10 \mathrm{~dB} / \mathrm{dec}$ ade with frequency. Moreover, absorption loss per Eq. 5 is proportional to the square root of the frequency 
and increases at a rate of $10 \mathrm{~dB} /$ decade with frequency. In this study, the values for $S E_{R}$ and $S E_{A}$ became equal at $15 \mathrm{GHz}$. Since this frequency was very close to the maximum testing frequency (18 GHz), the main shielding mechanism for almost the entire studied frequency range was reflection.

It is also notable that for frequencies under $1 \mathrm{GHz}$ where the graphene film thickness is smaller than the skin depth, $S E_{M R}$ is negative terms which means the multiple reflections adversely affect the total shielding effectiveness. For frequencies above $1 \mathrm{GHz}$, the skin depth became smaller than the thickness of the graphene film and $S E_{M R}$ approaches zero.

Figure 9 shows the calculated SE along with the measured SE for the carbon fiber reinforced composite panels coated with the graphene film. As it can be seen, the calculated SE closely follows the measured SE. The observed difference between the calculated and measured values of shielding effectiveness could be due to the formation of surface impedance and, in turn, the surface resistance and surface inductance at higher frequencies [50].

Figure 10 depicts the effect of graphene thin film thickness on EMI shielding effectiveness calculated at $100 \mathrm{MHz}$ using Eq. 4 through Eq. 6. As the figure shows, all three components of shielding effectiveness, i.e. $S E_{R}, S E_{A}$, and $S E_{M R}$ increase by reducing the thin film thickness resulting in more pronounced $S E_{\text {Total }}$ values. This could be attributed mainly to the enhancement of electrical conductivity as a result of reducing the thin film thickness. Figure 11 compares the $S E_{\text {Total }}$ measured over the frequency range of 8 to $12 \mathrm{GHz}$ in current study against the highest $S E_{\text {Total }}$ reported by Chen et al. [51] for multiple stacked graphene/PDMS foam composites, and Song et al. [38] for G-E film with 60 vol\% filler loading at thicknesses of 350 $\mu \mathrm{m}$, and Liang et al. [15] for graphene/epoxy composite with $15 \mathrm{wt} \%$ loading. As the figure shows, the value of $S E_{\text {Total }}$ reported in current study is higher than values reported in the previous 
studies which indicates the graphene thin film fabricated in current study features improved electrical conductivity hence better EMI shielding. The observed difference in electrical conductivity between the current and previous studies could be attributed to a number of factors including the fabrication method and the film stacking order.

\section{Conclusions}

The fabricated thin flexible nanocomposite coating made of pristine graphene could effectively improve the protection of a commercial carbon fiber epoxy prepreg laminate against the lightning strike. Particularly, the coating reduced the damage area and volume of the simulated lightning strike in the prepreg by $94 \%$ and $96 \%$, respectively. Moreover, the coating improved the EMI shielding effectiveness of the laminate by $22 \%, 44 \%$, and $49 \%$ over the microwave range (100-2000 MHz), X-band (8-12 GHz), and Ku-band (12-18 GHz), respectively. The observed improvements were mainly attributed to the superior electrical conductivity of the graphene thin film. Also, the fabricated thin film was very lightweight and flexible capable of taking contoured shapes and complicated geometries making it a viable replacement for the metallic meshes currently used in industry for protecting the composites structures against the lightning strikes and EMI shielding.

\section{Acknowledgment}




\section{References}

[1] Mahapatra P, Doviak R, Mazur V, Zrnić D. Aviation weather surveillance systems: advanced radar and surface sensors for flight safety and air traffic management: Institution of Electrical Engineers; 1999.

[2] Zantout A, Zhupanska O. On the electrical resistance of carbon fiber polymer matrix composites. Composites Part A: Applied Science and Manufacturing. 2010;41(11):1719-27.

[3] Tianchun Z, Jin W, Keyi M, Zhenyu F. Simulation of lightning protection for composite civil aircrafts. Procedia Engineering. 2011;17:328-34.

[4] Abu Obaid A, Yarlagadda S. Structural performance of the glass fiber-vinyl ester composites with interlaminar copper inserts. Composites Part A: Applied Science and Manufacturing. 2008;39(2):195-203. [5] Black S. Lightning strike protection strategies for composite aircraft. High-Performance Composites May 2013.

[6] Gardiner G. Lightning Strike Protection For Composite Structures. High-Performance Composites July 2006.

[7] Zhang B, Patlolla V, Chiao D, Kalla D, Misak H, Asmatulu R. Galvanic corrosion of Al/Cu meshes with carbon fibers and graphene and ITO-based nanocomposite coatings as alternative approaches for lightning strikes. Int J Adv Manuf Technol. 2013;67(5-8):1317-23.

[8] Gou J, Tang Y, Liang F, Zhao Z, Firsich D, Fielding J. Carbon nanofiber paper for lightning strike protection of composite materials. Composites Part B: Engineering. 2010;41(2):192-8.

[9] Zhang D, Ye L, Deng S, Zhang J, Tang Y, Chen Y. CF/EP composite laminates with carbon black and copper chloride for improved electrical conductivity and interlaminar fracture toughness. Composites Science and Technology. 2012;72(3):412-20.

[10] Chou T-W, Gao L, Thostenson ET, Zhang Z, Byun J-H. An assessment of the science and technology of carbon nanotube-based fibers and composites. Composites Science and Technology. 2010;70(1):1-19.

[11] Morales G, Barrena MI, Gómez de Salazar JM, Merino C. Conductive CNF-doped laminates processing and characterization. Journal of Composite Materials. 2011;45(20):2113-8.

[12] Yamamoto N, Guzman de Villoria R, Wardle B. Electrical and thermal property enhancement of fiber-reinforced polymer laminate composites through controlled implementation of multi-walled carbon nanotubes. Composites Science and Technology. 2012;72(16):2009-15.

[13] Domingues D, Logakis E, Skordos A. The use of an electric field in the preparation of glass fibre/epoxy composites containing carbon nanotubes. Carbon. 2012;50(7):2493-503.

[14] Zhang B, Asmatulu R, Soltani SA, Le LN, Kumar SSA. Mechanical and thermal properties of hierarchical composites enhanced by pristine graphene and graphene oxide nanoinclusions. Journal of Applied Polymer Science. 2014:in press.

[15] Liang F, Zhuge J, Algozzini L, Tang Y, Ren X, Lin K, et al. Electromagnetic interference shielding and lightning strike protection of carbon nanofiber paper. SAMPE Spring Symposium. Baltimore, MD 2009.

[16] Klemperer C, Maharaj D. Composite electromagnetic interference shielding materials for aerospace applications. Composite Structures. 2009;91(4):467-72. 
[17] Apra M, D'Amore M, Gigliotti K, Sarto M, Volpi V. Lightning indirect effects certification of a transport aircraft by numerical simulation. IEEE Transactions on Electromagnetic Compatibility. 2008;50(3):513-23.

[18] Society of Automotive E. Aircraft lightning environment and related test waveforms. [Warrendale, Pa.]: SAE International; 2005.

[19] Bhadra S, Singha NK, Khastgir D. Dielectric properties and EMI shielding efficiency of polyaniline and ethylene 1-octene based semi-conducting composites. Current Applied Physics. 2009;9(2):396-403.

[20] Li Y, Chen C, Li J-T, Zhang S, Ni Y, Cai S, et al. Enhanced Dielectric Constant for Efficient Electromagnetic Shielding Based on Carbon-Nanotube-Added Styrene Acrylic Emulsion Based Composite. Nanoscale Research Letters. 2010;5(7):1170 - 6.

[21] Sohi NJS, Rahaman M, Khastgir D. Dielectric property and electromagnetic interference shielding effectiveness of ethylene vinyl acetate-based conductive composites: Effect of different type of carbon fillers. Polymer Composites. 2011;32(7):1148-54.

[22] Thomassin J-M, Pagnoulle C, Bednarz L, Huynen I, Jerome R, Detrembleur C. Foams of polycaprolactone/MWNT nanocomposites for efficient EMI reduction. Journal of Materials Chemistry. 2008;18(7):792-6.

[23] Namai A, Kurahashi S, Hachiya H, Tomita K, Sakurai S, Matsumoto K, et al. High magnetic permeability of magnets in the millimeter wave region. Journal of Applied Physics. 2010;107(9):09A95509A-3.

[24] Huang R, Zhang D, Tseng KJ. Determination of Dimension-Independent Magnetic and Dielectric Properties for Mn-Zn Ferrite Cores and Its EMI Applications. Electromagnetic Compatibility, IEEE Transactions on. 2008;50(3):597-602.

[25] Jalali M, Dauterstedt S, Michaud A, Wuthrich R. Electromagnetic shielding of polymer-matrix composites with metallic nanoparticles. Composites Part B: Engineering. 2011;42(6):1420-6.

[26] Gooch JW, Daher JK. Electromagnetic shielding and corrosion protection for aerospace vehicles. New York; London: Springer; 2007.

[27] Chung DDL. Electromagnetic interference shielding effectiveness of carbon materials. Carbon. 2001;39(2):279-85.

[28] Shah T, Jones M, Alberding M, Laszewski M. Carbon Nanostructures for electromagnetic shielding and lightning strike protection applications in aircraft. ESA Workshop on Aerospace EMC. Venice, Italy 2012.

[29] Zhang B, Puttagounder D, Misak H, Kalla D, Asmatulu R. Development of highly conductive polymeric nanocomposite films on the surfaces of composites against lightning strikes. SAMPE Tech Conference. Fort Worth, TX 2011.

[30] Lan M, Cai J, Zhang D, Yuan L, Xu Y. Electromagnetic shielding effectiveness and mechanical property of polymer-matrix composites containing metallized conductive porous flake-shaped diatomite. Composites Part B: Engineering. 2014;67:132-7.

[31] Chen Y-J, Li Y, Chu BTT, Kuo IT, Yip M, Tai N. Porous composites coated with hybrid nano carbon materials perform excellent electromagnetic interference shielding. Composites Part B: Engineering. 2015;70:231-7.

[32] Ding Z, Shi SQ, Zhang H, Cai L. Electromagnetic shielding properties of iron oxide impregnated kenaf bast fiberboard. Composites Part B: Engineering. 2015;78:266-71.

[33] Mamunya Y. Carbon Nanotubes as Conductive Filler in Segregated Polymer Composites - Electrical Properties. Carbon Nanotubes - Polymer Nanocomposites: InTech Open; 2011.

[34] Brebbia CA, Klemm A. Materials Characterisation VI: Computational Methods and Experiments: WIT Press; 2013.

[35] Lee BO, Woo WJ, Park HS, Hahm HS, Wu JP, Kim MS. Influence of aspect ratio and skin effect on EMI shielding of coating materials fabricated with carbon nanofiber/PVDF. Journal of Materials Science. 2002;37(9):1839-43. 
[36] Jana PB, Mallick K, De SK. Effects of sample thickness and fiber aspect ratio on EMI shielding effectiveness of carbon fiber filled polychloroprene composites in the X-band frequency range. IEEE Transactions on Electromagnetic Compatibility. 1992;34(4):478-81.

[37] Thomassin J, Jérôme C, Pardoen T, Bailly C, Huynen I, Detrembleur C. Polymer/carbon based composites as electromagnetic interference (EMI) shielding materials. Materials Science and Engineering: R: Reports. 2013;74(7):211-32.

[38] Song W, Cao M, Lu M, Bi S, Wang C, Liu J, et al. Flexible graphene/polymer composite films in sandwich structures for effective electromagnetic interference shielding. Carbon. 2014;66:67-76.

[39] Kumar S. Incorporation of graphene thin films into the carbon fiber reinforced composite via $3 \mathrm{~d}$ composite concept against the lightning strikes on composite aircraft: M.Sc. Thesis in Mechanical Engineering; Wichita State University; 2012.

[40] DOD. MIL-STD-464C. 2010.

[41] Feraboli P, Miller M. Damage resistance and tolerance of carbon/epoxy composite coupons subjected to simulated lightning strike. Composites Part A: Applied Science and Manufacturing. 2009;40(6-7):954-67.

[42] Mall S, Ouper BL, Fielding JC. Compression Strength Degradation of Nanocomposites after Lightning Strike. Journal of Composite Materials. 2009;43(24):2987-3001.

[43] Feraboli P, Kawakami H. Damage response of carbon/ epoxy composite plates subjected to mechanical impact and simulated lightning strike. 2009 SAMPE Fall Technical Conference and Exhibition - Global Material Technology: Soaring to New Horizons, October 19, 2009 - October 22, 2009. Wichita, KS, United states: Soc. for the Advancement of Material and Process Engineering; 2009. p. SAMPE New Jersey Chapter; SAMPE Wichita Chapter.

[44] Alwarappan S, Kumar A. Graphene-Based Materials: Science and Technology: CRC Press; 2013.

[45] Wang FS, Ding N, Liu ZQ, Ji YY, Yue ZF. Ablation damage characteristic and residual strength prediction of carbon fiber/epoxy composite suffered from lightning strike. Composite Structures. 2014;117(0):222-33.

[46] Zheng G, Wu J, Wang W, Pan C. Characterizations of expanded graphite/polymer composites prepared by in situ polymerization. Carbon. 2004;42(14):2839-47.

[47] Paul CR. Introduction to Electromagnetic Compatibility: Wiley; 2006.

[48] Cao M-S, Song W-L, Hou Z-L, Wen B, Yuan J. The effects of temperature and frequency on the dielectric properties, electromagnetic interference shielding and microwave-absorption of short carbon fiber/silica composites. Carbon. 2010;48(3):788-96.

[49] Al-Saleh MH, Saadeh WH, Sundararaj U. EMI shielding effectiveness of carbon based nanostructured polymeric materials: A comparative study. Carbon. 2013;60(0):146-56.

[50] Nguyen C. Radio-Frequency Integrated-Circuit Engineering: Wiley; 2015.

[51] Chen Z, Xu C, Ma C, Ren W, Cheng H-M. Lightweight and Flexible Graphene Foam Composites for High-Performance Electromagnetic Interference Shielding. Advanced Materials. 2013;25(9):1296-300. [52] Gibson T, Putthanarat S, Fielding J, Drain A, Will K, Stoffel M. Conductive nanocomposites: Focus on lightning strike protection. SAMPE Tech Conference. Cincinnati, OH 2007.

[53] Imai M, Akiyama K, Tanaka T, Sano E. Highly strong and conductive carbon nanotube/cellulose composite paper. Composites Science and Technology. 2010;70(10):1564-70.

[54] Chen IH, Wang C-C, Chen C-Y. Fabrication and Structural Characterization of Polyacrylonitrile and Carbon Nanofibers Containing Plasma-Modified Carbon Nanotubes by Electrospinning. The Journal of Physical Chemistry C. 2010;114(32):13532-9.

[55] Singh AP, Garg P, Alam F, Singh K, Mathur RB, Tandon RP, et al. Phenolic resin-based composite sheets filled with mixtures of reduced graphene oxide, $\gamma$-Fe2O3 and carbon fibers for excellent electromagnetic interference shielding in the X-band. Carbon. 2012;50(10):3868-75.

[56] Yang Y, Gupta MC, Dudley KL, Lawrence RW. A Comparative Study of EMI Shielding Properties of Carbon Nanofiber and Multi-Walled Carbon Nanotube Filled Polymer Composites. Journal of Nanoscience and Nanotechnology. 2005;5(6):927-31. 
[57] Yang Y, Gupta MC, Dudley KL. Towards cost-efficient EMI shielding materials using carbon nanostructure-based nanocomposites. Nanotechnology. 2007;18(34):345701.

[58] Hoang AS. Electrical conductivity and electromagnetic interference shielding characteristics of multiwalled carbon nanotube filled polyurethane composite films. Advances in Natural Sciences: Nanoscience and Nanotechnology. 2011;2(2):025007. 


\section{Table Captions:}

Table 1: EMI shielding effectiveness of different nanocomposites.

Table 2: Thickness and electrical conductivity of thin films fabricated for this study.

Table 3: Analysis of damage area and volume due to simulated lightning strike for composite panels. 


\section{Figure Captions:}

Figure 1: Schematic of electromagnetic shielding mechanisms consisting of reflection, absorption, and multiple reflections [47].

Figure 2: Fabrication steps for graphene thin film.

Figure 3: (a) Schematic of $100 \mathrm{kA}$ lightning strike test simulation [52], and (b) classic simulated lightning current waveforms [40].

Figure 4: Schematic of reverberation chamber.

Figure 5: Flexibility of the fabicated graphene thin film.

Figure 6: 3-D images of area of damage and volume of damage for: (a) control panel, and (b) panel coated with graphene thin film.

Figure 7: EMI shielding effectiveness as a function of frequency over microwave range (100$2000 \mathrm{MHz}), \mathrm{X}$-band $(8-18 \mathrm{GHz})$, and $\mathrm{Ku}$-band $(12-18 \mathrm{GHz})$ for control panel and panel coated with graphene thin film.

Figure 8: Calculated EMI shielding effectiveness values and skin depth for the graphene thin film as a function of frequency.

Figure 9: Calculated and measured shielding effectiveness as a function of frequency for the panel coated with graphene thin film.

Figure 10: Calculated shielding effectiveness components vs. graphene thin film thickness.

Figure 11: $S E_{\text {Total }}$ over X-band reported in current study and previous studies. 
Table 1:

\begin{tabular}{|c|c|c|c|c|c|}
\hline Matrix & Filler Loading (wt. \%) & $\begin{array}{l}\text { Thickness } \\
(\mathbf{m m})\end{array}$ & $\begin{array}{l}\text { EMI SE } \\
\text { (dB) }\end{array}$ & $\begin{array}{l}\text { Frequency } \\
\text { (GHz) }\end{array}$ & Reference \\
\hline $\mathrm{ABS}$ & $2.5 \%$ Carbon Black & 1.1 & 1.3 & 10 & [49] \\
\hline ABS & $15 \%$ Carbon Black & 1.1 & 19 & 10 & [49] \\
\hline ABS & 1.5\% Carbon Nanofiber & 1.1 & 3.3 & 10 & [49] \\
\hline ABS & $15 \%$ Carbon Nanofiber & 1.1 & 34 & 10 & {$[49]$} \\
\hline ABS & $0.5 \%$ Carbon Nanotube & 1.1 & 7 & 10 & [49] \\
\hline ABS & 15\% Carbon Nanotube & 1.1 & 50 & 10 & {$[49]$} \\
\hline cellulose & 9.1\% Carbon Nanotube & 0.195 & 20 & $15-40$ & {$[37,53]$} \\
\hline Epoxy & $0.5 \%$ Graphene & $0.8-1.1 \times 10^{-6}$ & 1.2 & 10 & {$[15]$} \\
\hline Epoxy & $15 \%$ Graphene & $0.8-1.1 \times 10^{-6}$ & 21 & 10 & [15] \\
\hline PAN & $2 \%$ Carbon Nanotube & 0.150 & 20 & $0.3-3$ & {$[37,54]$} \\
\hline Phenolic & $80 \%$ Reduced Graphene Oxide & $0.2-0.4$ & 50.92 & 10.2 & [55] \\
\hline Phenolic & $\begin{array}{l}10 \% \text { Carbon Fiber, } 40 \% \\
\text { Reduced Graphene Oxide }\end{array}$ & $0.2-0.4$ & 21.61 & 10.2 & {$[55]$} \\
\hline PS & 5\% Carbon Nanotube & 1 & 25 & $8-12$ & {$[37,56]$} \\
\hline PS & $5 \%$ Carbon Nanofiber & 1 & 7.2 & $12.4-18$ & {$[57]$} \\
\hline PS & $10 \%$ Carbon Nanofiber & 1 & 12.9 & $12.4-18$ & [57] \\
\hline PS & Carbon Nanotube & 1 & 7.9 & $12.4-18$ & [57] \\
\hline PS & $5 \% \mathrm{CNF}, 1 \% \mathrm{CNT}$ & 1 & 14.4 & $12.4-18$ & [57] \\
\hline PS & $10 \% \mathrm{CNF}, 1 \% \mathrm{CNT}$ & 1 & 20.3 & $12.4-18$ & [57] \\
\hline PS & $10 \% \mathrm{CNF}, 3 \% \mathrm{CNT}$ & 1 & 21.9 & $12.4-18$ & [57] \\
\hline PUR & 22\% Carbon Nanotube & 0.1 & 20 & $8-12$ & {$[37,58]$} \\
\hline Styrene Acrylic Emulsion & $5 \%$ MWCNT & 1.5 & 5.7 & 10 & {$[20]$} \\
\hline Styrene Acrylic Emulsion & $20 \%$ MWCNT & 1.5 & 26 & 10 & [20] \\
\hline
\end{tabular}




\section{Table 2:}

\begin{tabular}{|c|c|c|}
\hline Number & $\begin{array}{c}\text { Thickness } \\
(\mathbf{m m})\end{array}$ & $\begin{array}{c}\text { Through-the-Thickness Electrical } \\
\text { Conductivity (S/m) }\end{array}$ \\
\hline 1 & $1.40 \times 10^{-1}$ & $1.32 \times 10^{4}$ \\
\hline 2 & $1.02 \times 10^{-1}$ & $2.14 \times 10^{4}$ \\
\hline 3 & $7.62 \times 10^{-2}$ & $4.54 \times 10^{4}$ \\
\hline 4 & $6.35 \times 10^{-2}$ & $5.61 \times 10^{4}$ \\
\hline 5 & $5.08 \times 10^{-2}$ & $7.24 \times 10^{4}$ \\
\hline 6 & $3.05 \times 10^{-2}$ & $1.25 \times 10^{5}$ \\
\hline 7 & $2.54 \times 10^{-2}$ & $1.54 \times 10^{5}$ \\
\hline 8 & $2.29 \times 10^{-2}$ & $1.76 \times 10^{5}$ \\
\hline
\end{tabular}


Table 3:

\begin{tabular}{|l|c|c|}
\hline & Control Panel (No Coating) & Panel Coated with Graphene Thin Film \\
\hline Damage Area $\left(\mathbf{m m}^{2}\right.$ ) & $1.39 \times 10^{4}$ & $8.77 \times 10^{2}$ \\
\hline Fraction of Damage Area (\%) & 5.4 & 0.3 \\
\hline Damage Area Reduction (\%) & - & 94 \\
\hline Damage Volume (mm $\left.\mathbf{m}^{\mathbf{3}}\right)$ & $7.07 \times 10^{3}$ & $3.06 \times 10^{2}$ \\
\hline Fraction of Damage Volume (\%) & 2.7 & 0.1 \\
\hline Damage Volume Reduction (\%) & - & 96 \\
\hline
\end{tabular}




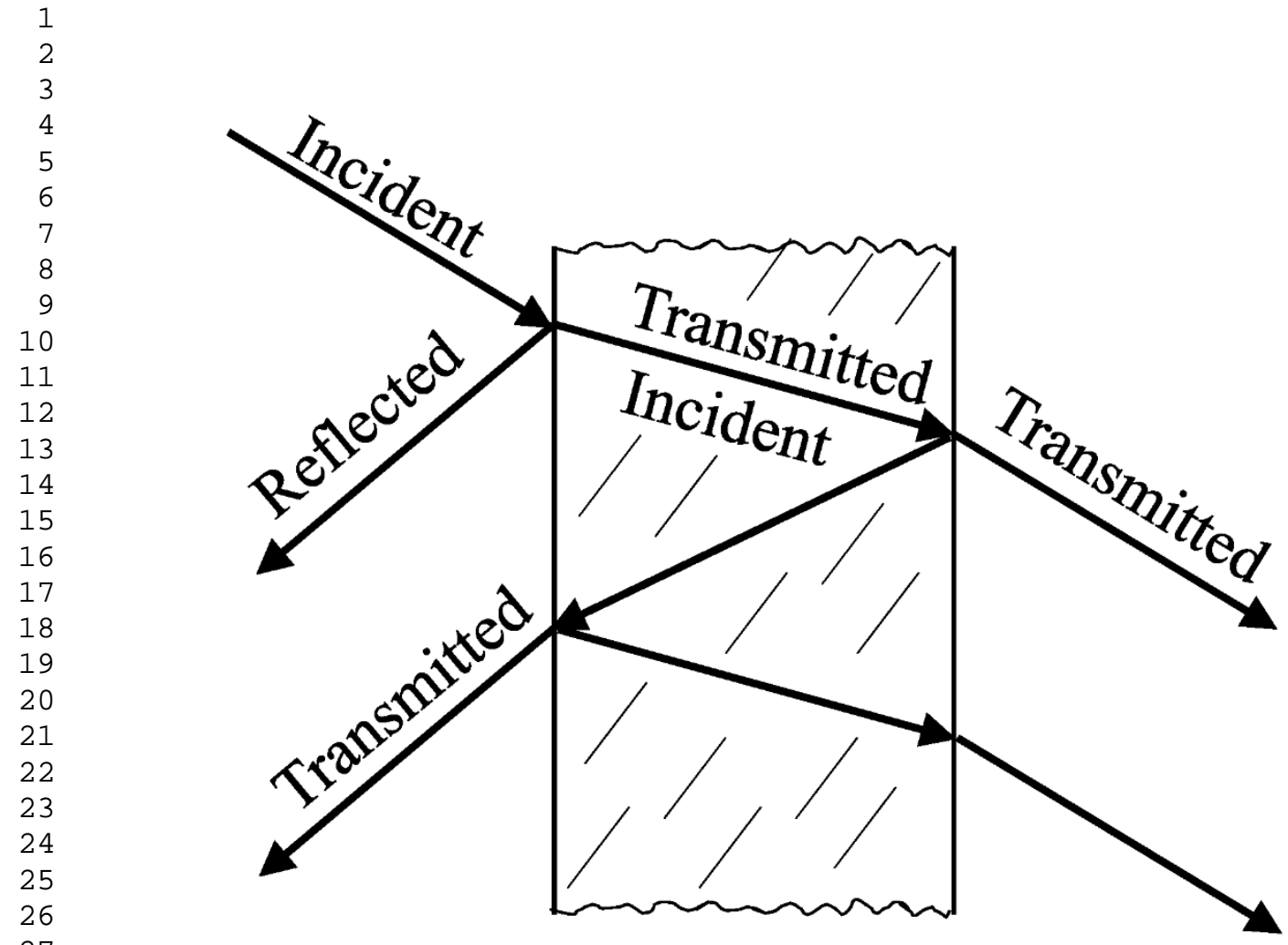

Figure 1: 
Al Al
Clamps

(a)

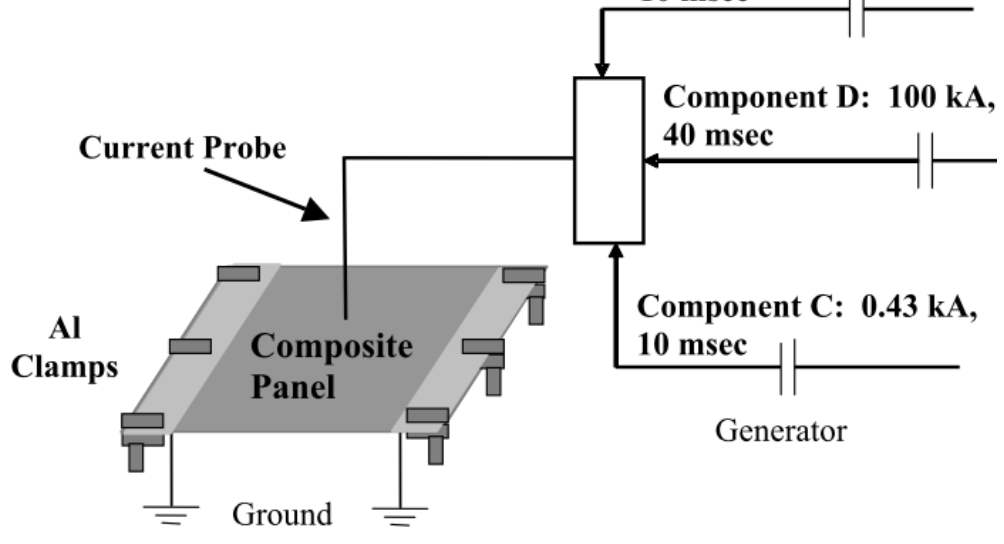

Component B: 3.9 kA,

$10 \mathrm{msec}$

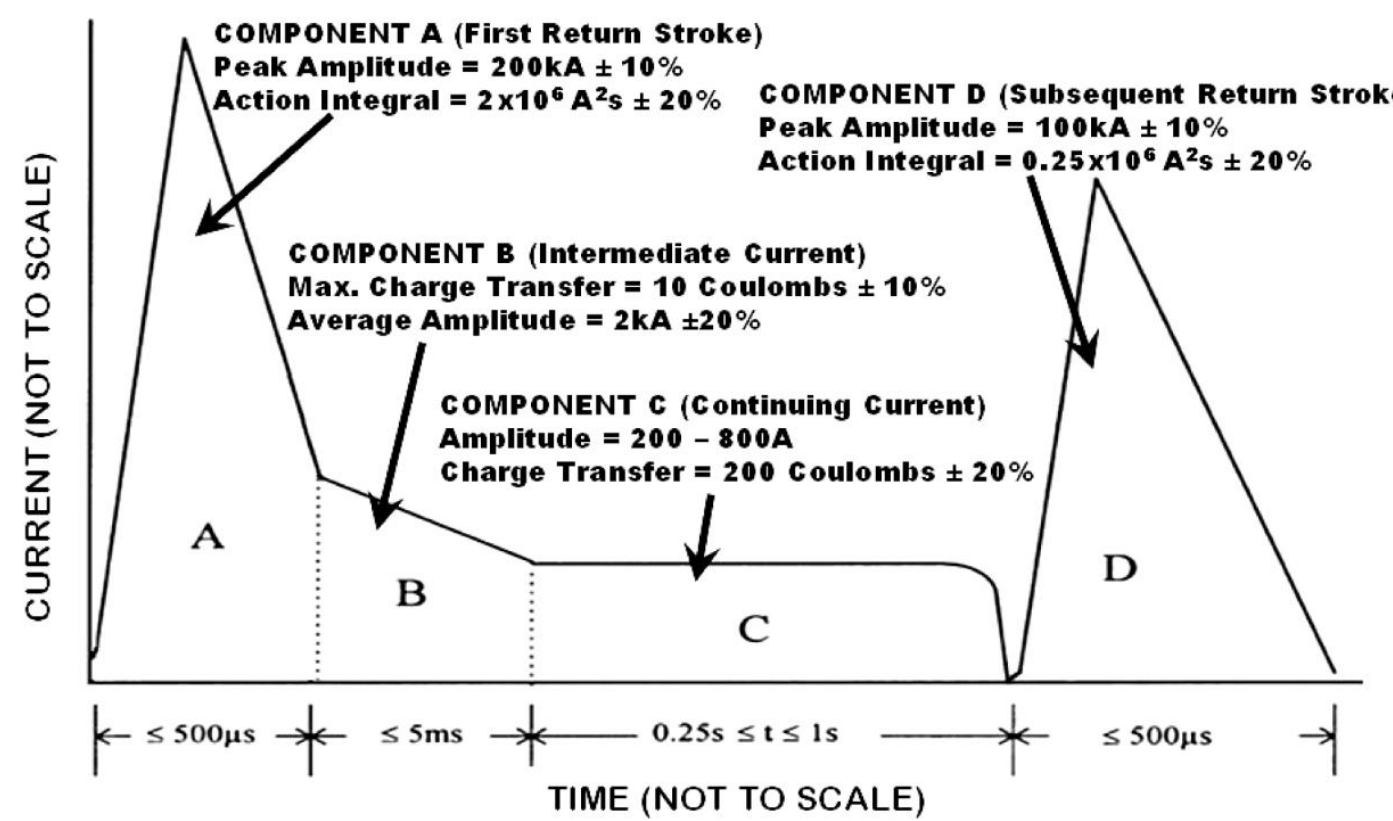

(b)

Figure 3: 
Spectrum

Analyzer

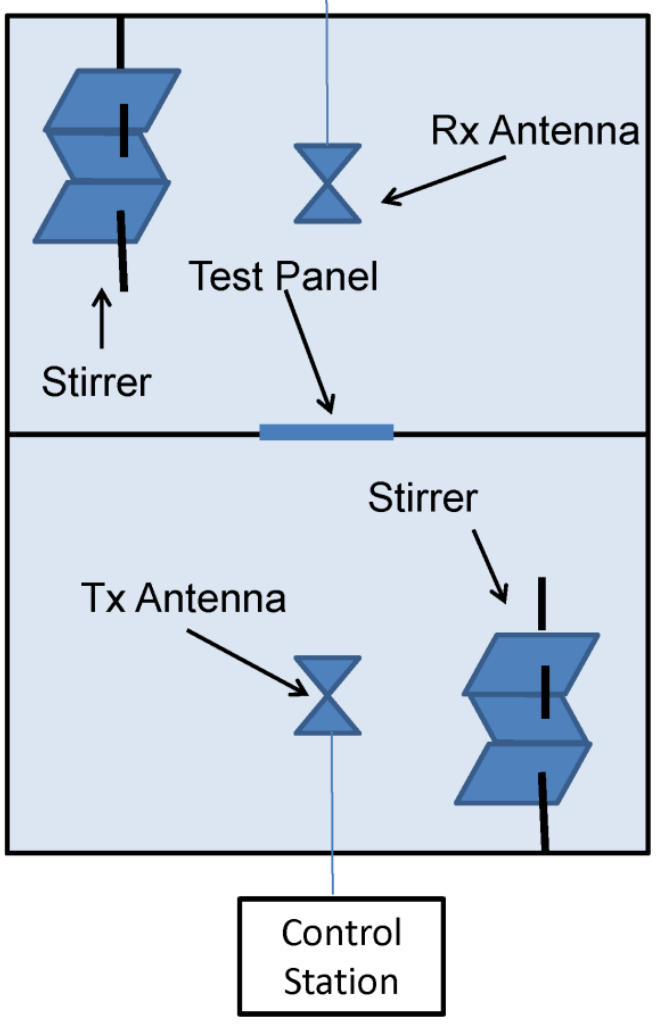

Figure 4: 


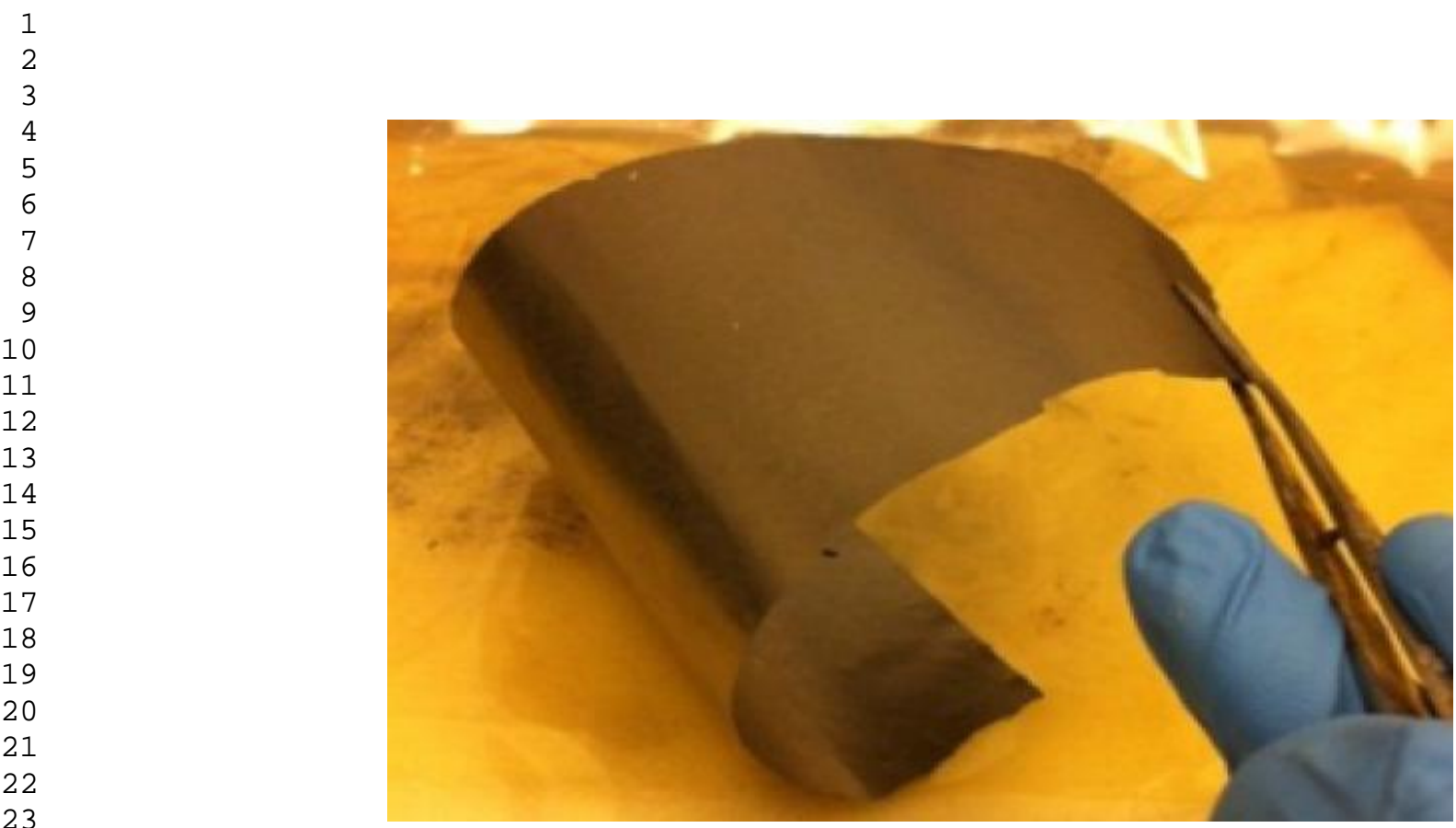

24

25

Figure 5:

27

28

29

30

31

32

33

34

35

36

37

38

39

40

41

42

43

44

45

46

47

48

49

50

51

52

53

54

55

56

57

58

59

60

61

62

63 


\section{Figure 6a:}

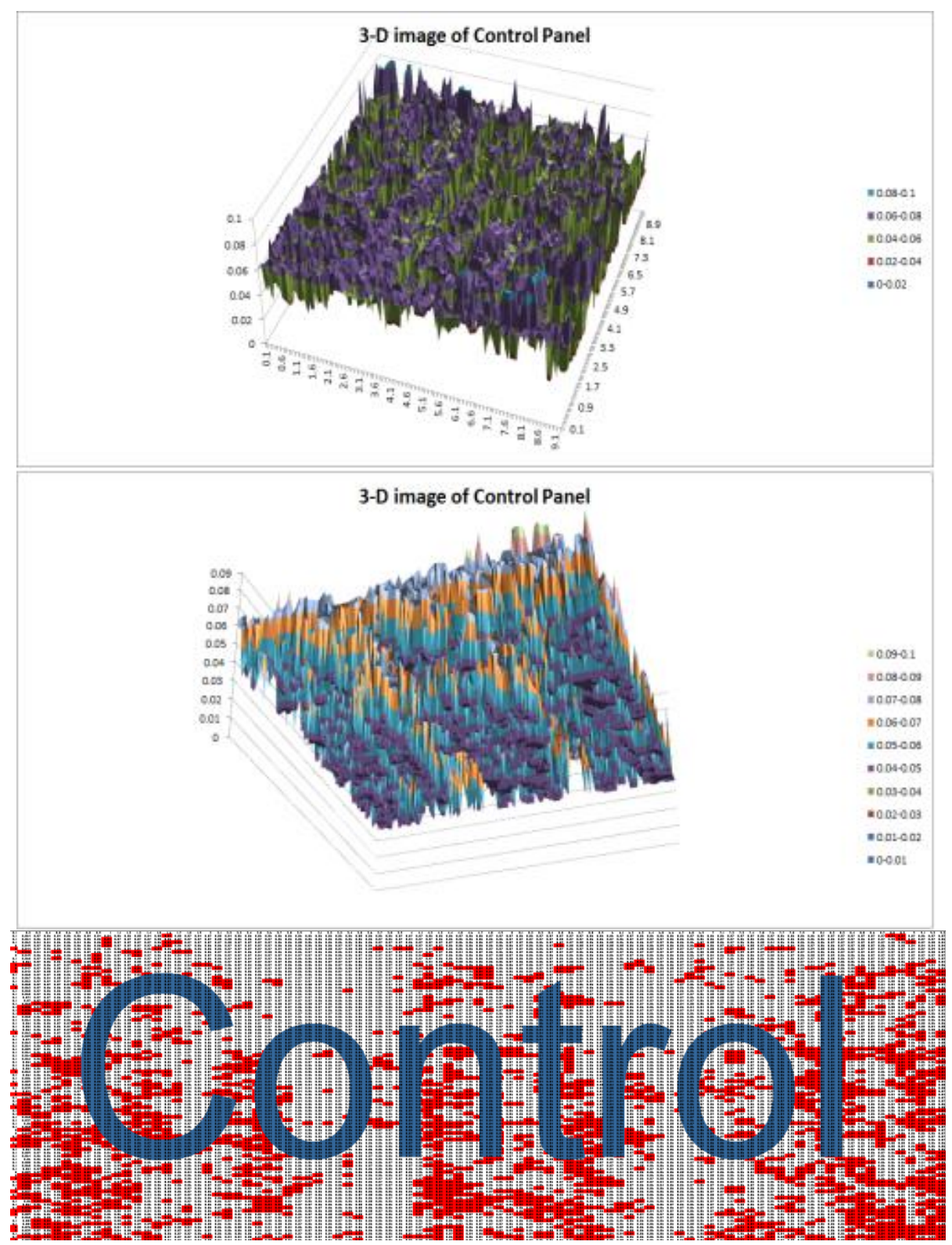

5

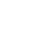

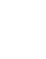

0

4

6

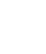

1

2

3




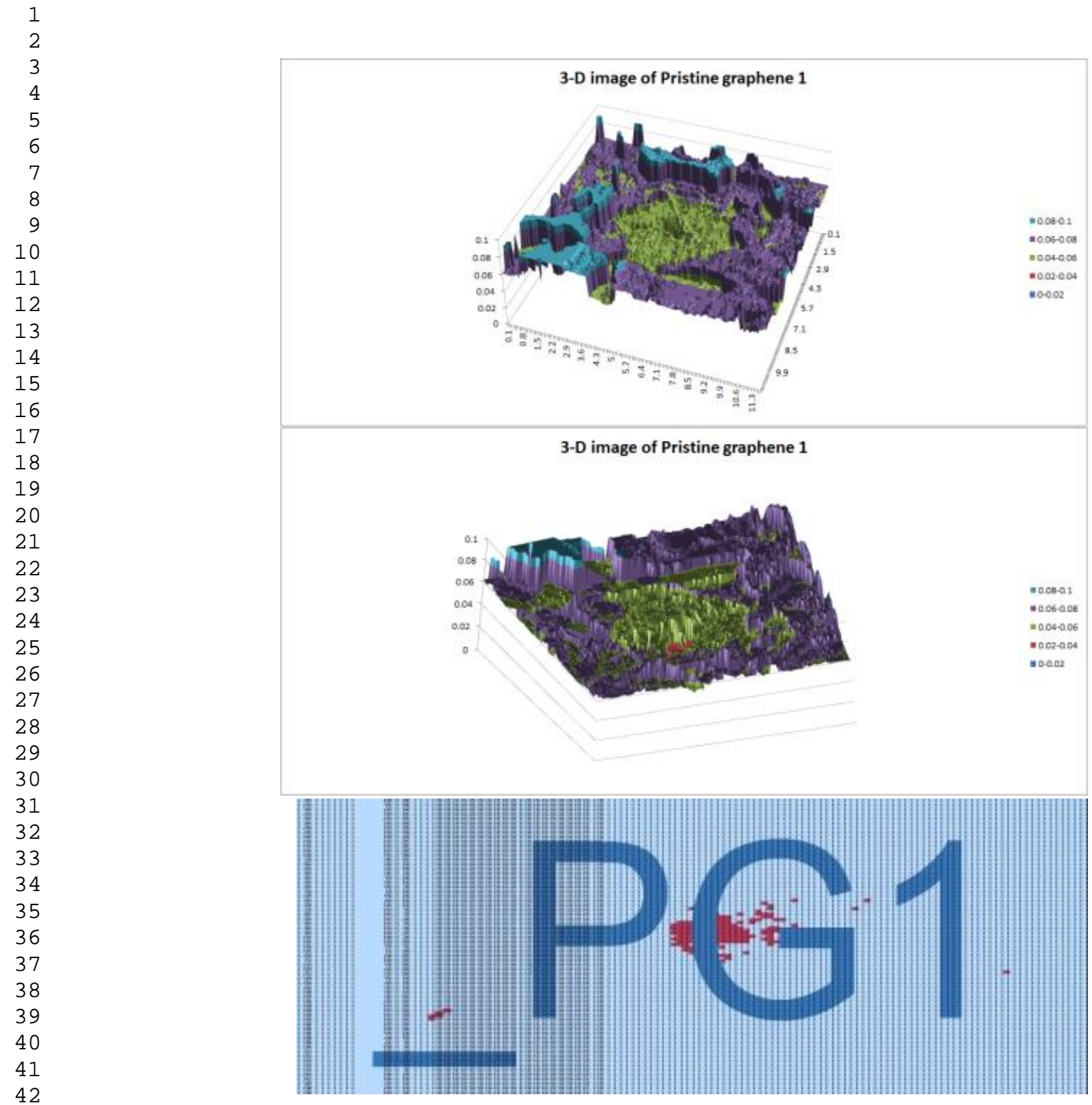

43

44 Figure 6b:

45

46

47

48

49

50

51

52

53

54

55

56

57

58

59

60

61

62 


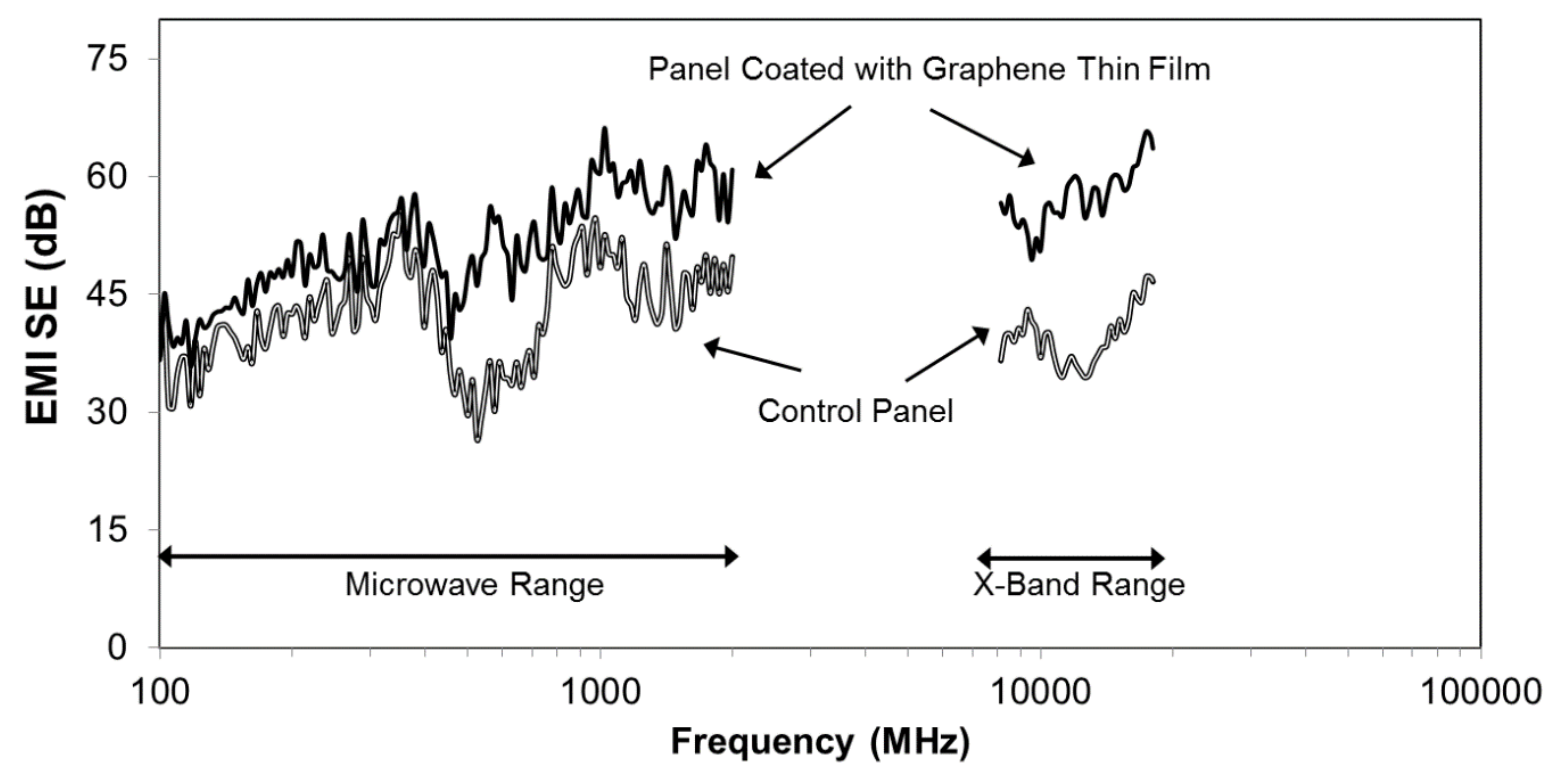

Figure 7:

24

25

26

27

28

29

30

31

32

33

34

35

36

37

38

39

40

41

42

43

44

45

46

47

48

49

50

51

52

53

54

55

56

57

58

59

60

61

62 


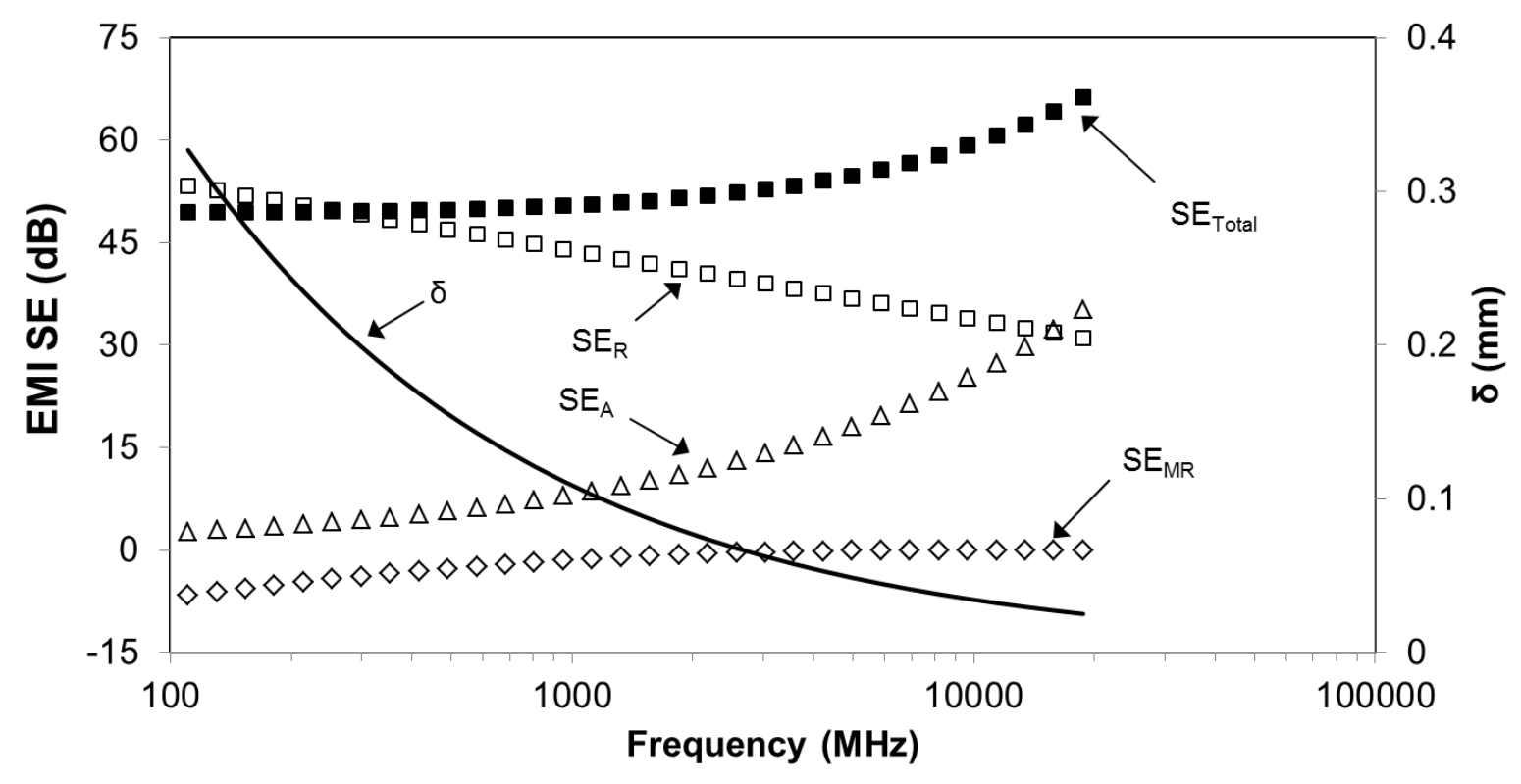

Figure 8: 


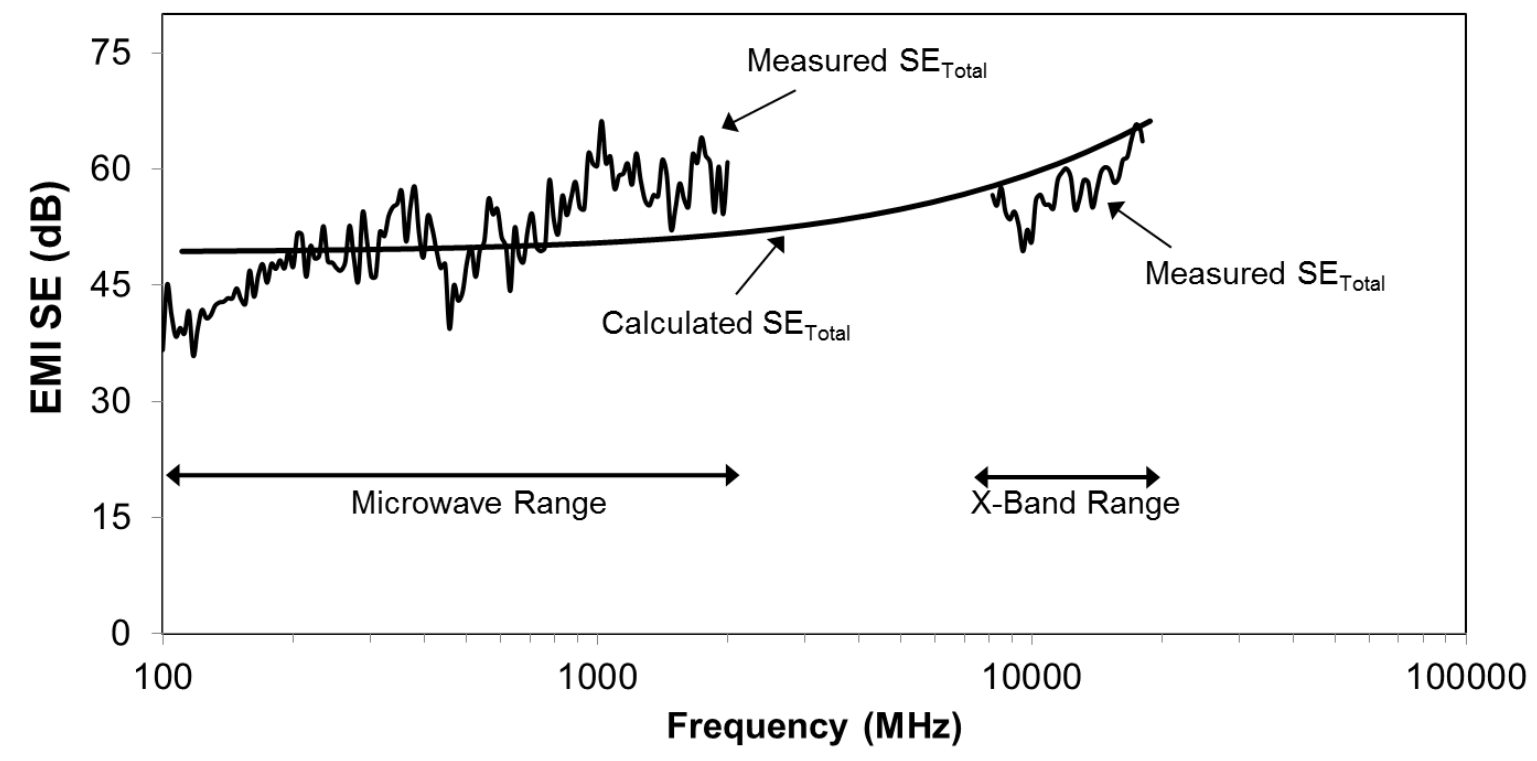

Figure 9:

27

28

29

30

31

32

33

34

35

36

37

38

39

40

41

42

43

44

45

46

47

48

49

50

51

52

53

54

55

56

57

58

59

60

61

62

63 


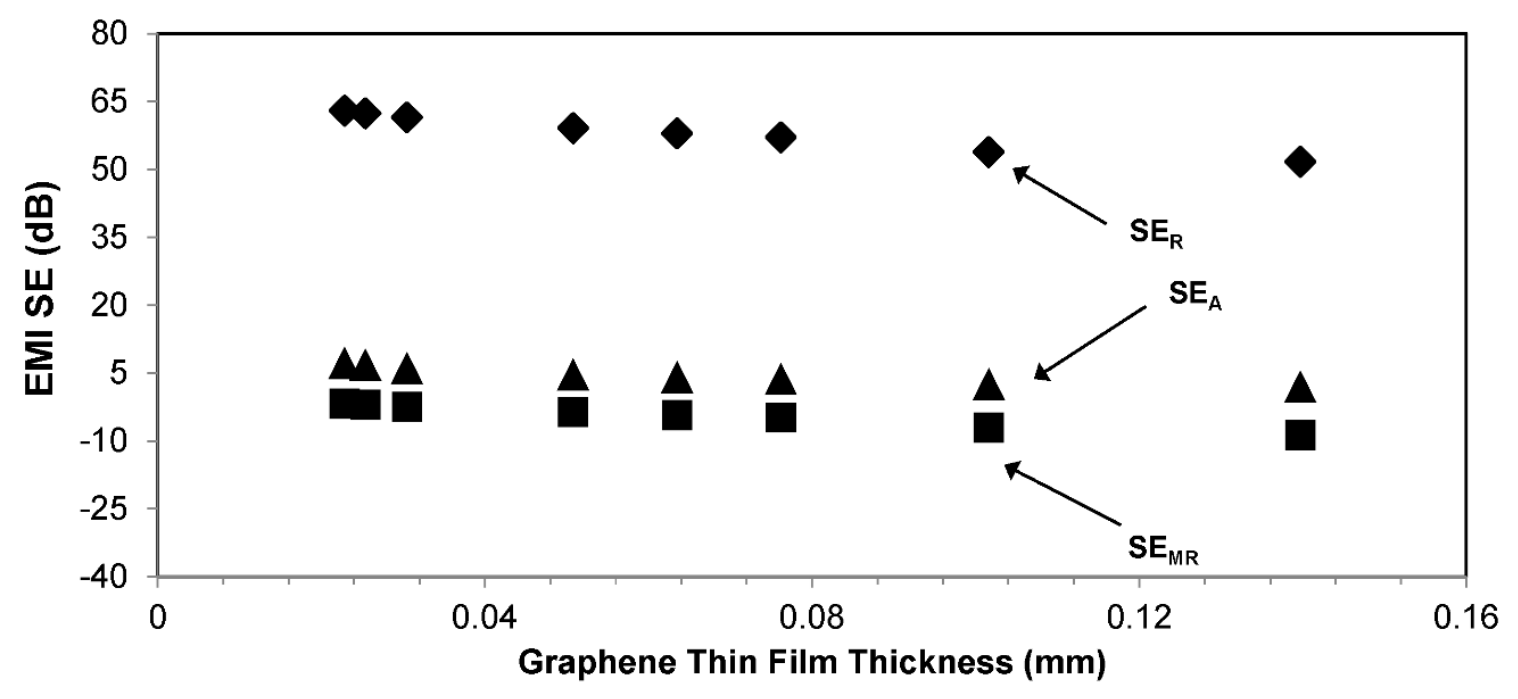

Figure 10:

21

22

23

24

25

26

27

28

29

30

31

32

33

34

35

36

37

38

39

40

41

42

43

44

45

46

47

48

49

50

51

52

53

54

55

56

57

58

59

60

61

62

63 


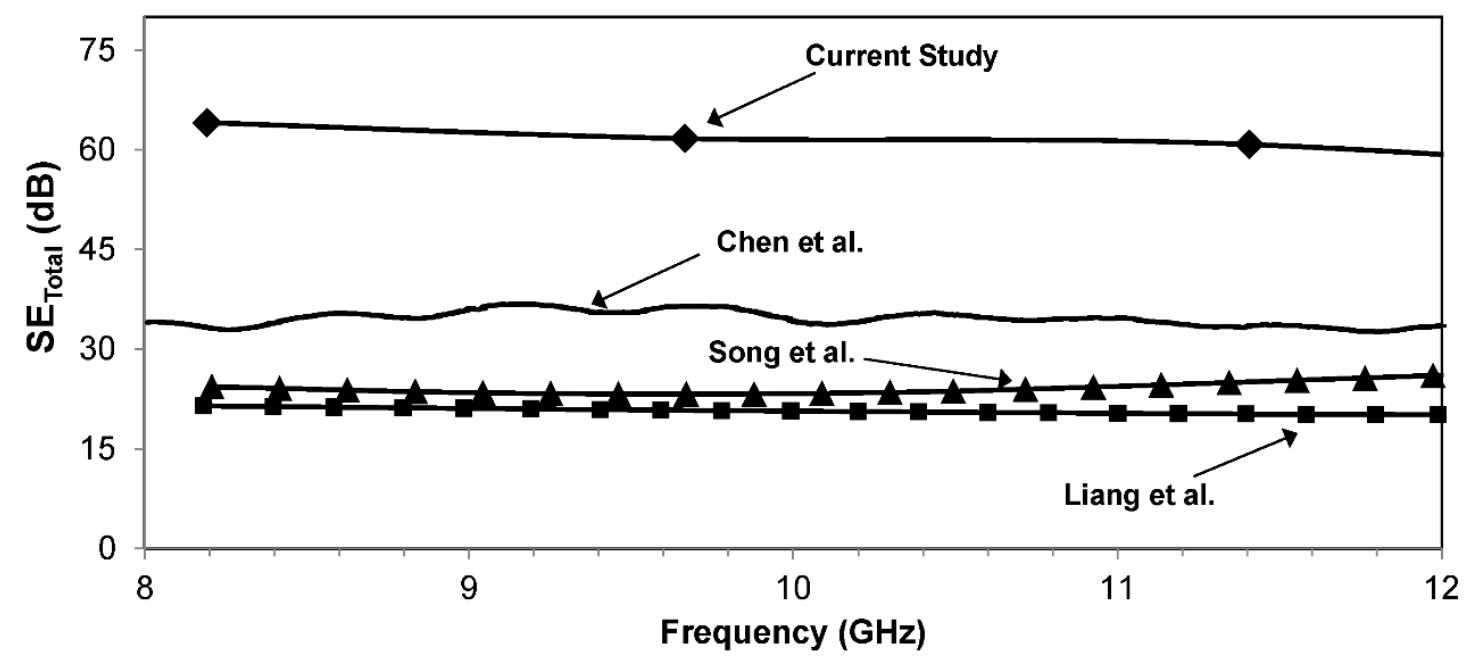

\section{Figure 11:}

